\title{
O Instituto da Readaptação
}

$\cos$ Civis)

- Lei $\mathrm{n}^{\circ}$ 1.711, de 1952 (Estatuto dos Funcionários Públi-

- Lei n 3.780, de 1960 (Plano de Classificação de Cargos)

- Lei $n^{2} 4.878$, de 1965 (Estatuto do Policial).

\section{WALDYR DOS SANTOS}

\section{I - Na Administração Pública}

A readaptação da Lei $\mathrm{n}^{\curvearrowleft} 1.711$ aparece como um instrumento necessário à correção de um estado de fato - o desajuste entre o servidor público e as atribuições do cargo em que se encontra efetivamente provido, resultante da redução de sua capacidade física ou intelectual, ou do conflito de vocação.

A readaptação da Lei $n^{\circ} 3.780$ é instituída como instrumento necessário à correção, também, de um estado de fato, a existência, no Serviço Público, de funcionário desempenhando atribuições completamente estranhas ao cargo de que é titular efetivo, circunstância essa oficialmente conhecida através da pesquisa para a elaboração do Plano de Classificação.. (Em determinada categoria de cargos foi verificado que 88 em 100 dos servidores não exerciam funções do respectivo cargo).

Surgindo, assim, de necessidades diversas, êsses dois institutos, com a mesma nomenclatura (readaptação), tiveram configuraçâo legal própria.

No primeiro caso, o reajuste se impunha como meio permanente de se corrigir: 1) a modificação do estado físico ou das condiçóes de saúde do servidor; ou 2) a falta de correspondência do desenvolvimento do nível mental em relação às exigências do exercício das atribuições do cargo, ou mesmo de pendores vocacionais para êsse exercício.

A correção, visando à eficiência funcional do servidor, no caso, configurou-se na expressão legal de «investidura em função mais compativel com a capacidade do funcionário» (art. 70, Lei n? 1.711 52).

Para o legislador a especificação da capacidade física ou intelectual, assim como a de vocação, estariam implicitas na noção do têrmo readaptação. 
A forma de sua efetivação seria a do instituto da transferência (art. 71, Lei $\mathrm{n}^{\circ} 1.711$ ), transferência readaptadora portanto - que se processa, afinal, ex officio (art. 52, II, Lei $\mathrm{n}^{\circ} 1.711$ ), com imposição da regra estatutária absoluta do condicionamento a concurso. Nesse aspecto, ocorreu verdadeira regressão do instituto, tornando-o quase inaplicável.

Davam-lhe, ainda, a natureza da compulsoriedade e a exigência de exame de saúde, na sua aplicação.

Já o instituto da readaptação da Lei $\mathrm{n}^{\circ} 3.780$, objetiva reajustar o servidor nas funçốes exercidas durante determinados períodos (desvio funcional), como complementação à implantação do sistema de classificação de cargos que se instituía, pelá primeira vez, no Serviço Público Brasileiro (Lei n 3.780-60).

Como é tradicional no serviço público, as normas legais estabelecendo proibições raramente são rigorosamente observadas, principalmente quando teòricamente recomendadas. A proibição do exercício de atividades diversas às inerentes ao cargo ou carreira a que pertencia o funcionário constituía determinação legal desde 1939, com o artigo 272 da Lei $n^{\circ} 1.713$, e ratificada em 1952 (art. $7^{\circ}, \S 3^{\circ}$, Lei $n^{\circ} 1.711$ ). Assim é que não obstante aquela determinação, o levantamento de dados para estudo e elaboração do plano de classificação de cargos veio revelar que servidores, em número não pequeno, como ocupantes de funções policiais exerciam tarefas burocráticas; escriturários funcionavam como médicos, dentistas e assim por diante.

Mas sabiam os técnicos que a solução para o problema do desvio funcional, em sua totalidade, não seria encontrado na simples classificação de cargos, por isso instituiu-se a readaptação, como meio de gradativamente corrigir aquelas anomalias, respeitados os direitos dos servidores.

À proposta de aplicação do instituto aos desvios funcionais, ocorridos por necessidade comprovada do serviço, com duraçâo de tempo ininterrupto superior a três anos, preferiu o legislador fixar, em virtude do longo tempo em que o projeto permaneceu no Congresso (de 1954 e 1960), períodos delimitados para caracterizar o desvio funcional: prazo ininterrupto superior a dois anos (no minimo de 12 de julho de 1958 a 12 de julho de 1960); ou por mais de cinco anos, também ininterruptos até 21 de agôsto de 1959 (no mínimo de $21-8-54$ a 21-8-59) (art. 43 da Lei $\mathrm{n}^{\circ} 3.780$, publicada a 12 de julho de 1960).

Ao estabelecer êsses periodos, o mesmo diploma legal (Lei n ${ }^{\circ}$ 3.780) determinava, novamente, proibição de se conferir, a qualquer servidor, atribuições diversas das pertinentes à classe em que fôra enquadrado e acrescentava:

«Em caso algum poderá tal fato acarretar a reclassificação do funcionário ou a sua readaptação.» 
Com isto, confessava-se a descrença de que novos desvios funcionais não ocorressem, mesmo diante da cominação da pena de demissão ou destituição de função do chefe responsảvel (art. 47) pela sua ocorrência. Entretanto, tudo era facilitado pela inexistência de uma especificação de classes, que sòmente agora, mais de sete anos passados, vem de ser objeto de atenção da administração pública.

E a continuação dos desvios funcionais vinha levar o legis lador a incluir, em proposição legislativa, dispositivo ampliando os períodos, anteriormente fixados, para caracterização dos mesmos (art. 64, Lei $\mathrm{n}^{2}$ 4.242 63), fundamentado nas mesmas razões que justificaram a instituição da readaptação como instrumento de correção. Agora, então, caracterizava também, como desvio funcional, o exercício de atribuições diversas das do cargo em que se encontrava provido o funcionário nos períodos: de dois anos ininterruptos até à vigência da Lei $n^{\circ} 4.242$, de 1963 $(17-7-63)$, e de cinco anos, mesmo interrompidos, até essa data $(17-7-63)$, desde que estivesse naquelas funções também a 12-7 -60, data da vigência da Lei $n^{0} 3.780-60$.

Visando, dessa forma, a corrigir anomalias por desvios funcionais, portanto, de caráter transitório, a readaptação da Lei $\mathrm{n}^{\circ} 3.780-60$, foi prevista para ser efetivada mediante transformação do cargo (art. 45), e, ao contrário da outra espécié (Lei $\left.\mathrm{n}^{\circ} 1.711\right)$ de aplicação permanente, não só ex officio mas podendo ser solicitada pelo funcionário desviado de função.

A princípio, pretendeu-se, no projeto inicial, corrigir o desvio funcional encontrado, como realidade anômala, com a aplicação da readaptação estatutária, mas essa pretensão não logrou sucesso, assumindo o instituto portanto a configuração própria, nos artigos 43 e seguintes da Lei n: 3.780 , em face dos aspectos específicos da correção que se exigia.

Como instrumento permanente de aplicação, para reajuste de servidores em funções mais compativeis com a sua capacidade do momento, o Estatuto do Policial (Lei no 4.878, de 3-12-65) consignou o instituto da readaptação, num misto dos dois existentes (Leis ns. 1.711 e 3.780), tornando o, assim, um meio eficaz e pronto para solução do desajustamento funcional, com benefício para o serviço público e para o servidor, contribuindo para maior eficiência do primeiro e para a valorização do segundo.

Eis os têrmos do artigo 20 da Lei $n^{\circ} 4.878$ :

«O funcionário policial que, comprovadamente, se revelar inapto para o exercício da função policial sem causa que justifique a sua demissão ou aposentadoria, será readaptado em outro cargo mais compativel com a sua capacidade, sem decesso nem aumento de vencimento.» 
Parágrafo único. A readaptação far-se-á mediante a transformação do cargo exercido em outro mais compativel com a capacidade física ou intelectual e vocação.»

A restrição - sem decesso ou aumento de aumento de vencimento - é comum às readaptações das Leis ns. 1.711 e 4.878 , diferentemente do que dispõe a Lei $n^{\circ} 3.780$. E essa diferença explica-se porque, no caso dêste último diploma, a medida resulta do reconhecimento de uma situação de fato, diversa, como a do exercício, já em ocorrência, de atribuições de outro cargo, portanto exigindo uma contraprestação (pagamento) à altura de sua natureza.

\section{II - NO JUDICIÁRIO}

Talvez impressionado com a utilização desfigurada, exagerada e inadequada, nos últimos tempos, do instituto do Mandado de Segurança, em assuntos relativos a servidores públicos, os Tribunais começam a fixar jurisprudência vedando-o como meio de ação para efeito de reconhecimento de direito a readaptação e enquadramento.

Nesse sentido se colocam:

O Supremo Tribunal Federal em decisões como:

Readaptação. Mandado de Segurança indeferido. (Mandado de Segurança (MS) 16.020-DF, in Diário da Justiça (DJ) de 15-6-66, página 2.100; Recurso em Mandado de Segurança (RMS) 16.495-SP, DJ. 24-6-66, p. 2.262; RMS 16.496-SP, in Revista Trimestral de Jurisprudência (RTJ), Volume (v) 38, p. 193; MS 14.202-DF, DJ 23-3-66, p. 868 e RTJ V 36 p. 270).

Aliás orientação dentro do espírito da Súmula 270 e decisões: RMS 17.006-GB, DJ 26-4-67, p. 1.135; MS 9.933-DF, DJ $4-5-66$, p. 1.429; RMS 15.589 , DJ 5-10-66 p. 3.381; RMS 16.274, DJ 5-10-66, p. 3.381; RMS 17.636-SP, DJ 26-5-67, p. 526 .

O Tribunal Federal de Recursos em julgados no sentido de que o "writ of mandamus» não constitui meio idôneo para examinar atos de classificação de cargos ou de readaptação, que geralmente envolvem o mérito de questões de alta indagação, dependendo para sua apreciação de numerosos elementos de fatos e confronto de situaçóes. Agravo em Mandado de Segurança (AMS) 45.817-GB, DJ 28-1-66, Apenso p. 30; AMS 48.621SP. DJ 7-12-66, p. 4.321; Apelação Cível (Ap) 28.372-CE, DJ $22-5-67$, p. 1.466; AMS 43.723, DJ 2-9-66 p. 2.965; 43.976-GB, DJ 6-5-66 p. 1.473; 45.641-SP, DJ 6-5-66, p. 1.474; 43.600-SP, DJ 30-9-66, p. 3.349; 56.044-SP, DJ 9-9-66, 
p. $3.041 ; 31.521-\mathrm{DF}$, DJ $30-9-66$, p. 3.345; 51.425-SP, DJ 25 de novembro de 1966, p. 4.146; 42.447-SP, DJ 31-10-66, p. $3.786 ; 45.512-S P$, DJ $22-5-67$, p. $1.468 ; 43.603-S P$, DJ 14 de outubro de 1966, p. 3.561).

Inúmeros outros julgados foram expedidos pelo Judiciário, nesse sentido, mas, mesmo assim, ainda há funcionários que tentam ter o seu direito à aplicação do enquadramento e da readaptação por via mandamental.

Decide, ainda, o Tribunal Federal de Recursos:

«A readaptação está na dependência de um processo administrativo, para indagação e prova dos requisitos que a justificam. A sentença sobretudo em mandado de segurança, não pode substituílo» (AMS 32.556-GB, DJ 30-5 66, p. 1.823; 39.366SP, ibidem, p. 1.825; 45.500-SP, DJ 13 6-66, p. 2.061; 45.558-SP, ibidem, p. 2.061; 42.623-SP, ibidem, p. 2.060; 46.064-SP, DJ $4-7-66$, p. 2.353 ; MS 32.873 , DJ $21-9-64$, p. $3.391 ; 32.164$, DJ 2-9-64, p. 3.154; AMS 47.712-SP, DJ 29-4-66, p. 1.375; 45.072-SP, DJ 23-5 66, p. 1.708; 40.276-SP, DJ 4-4-66, p. 1.080 ; 41.547-SP, ibidem, p. 1.081; 51.591 SP, DJ 21-10-66, p. 3.688; 40.152-SP, DJ 24-2 -67, p. 335).

E, acrescenta, também, com relação à exigência de processo administrativo:

«A sentença, mesmo em ação ordinária, não pode substituílo» (Ap. 22.550-DF, DJ 21 10 66, p. 3.693);

porque

«Nem sempre a ação, mesmo ordinária, esclarece todos os dados, provas e contraprovas» (Ap. 20.366-RS, DJ 21-10-66, p. 3.692).

Elege, assim, a jurisprudência do Colendo Tribunal Federal de Recursos, como condição fundamental para a via judiciária, o prévio processo administrativo.

Não só porque

«A readaptação só pode e deve ser apreciada, originàriamente, mediante a perquirição dos fatos em que se baseia, o que escapa à via heróica e expedita do mandado de segurança» (AMS 50.218 SP, DJ 22-8-66, p. 2.777; 50.305-SP, ibdem, p. 2.778; 51.422-SP, DJ 21 10-66, p. 3.688; 47.308-SP, DJ 18-11-66, p. 4.028; Ap. 23.009-GB, DJ 21 12 66, p. 4.485)

Mas, igualmente, porque

«O pedido de readaptação deve ser processado administrativamente, havendo, porém, exercício de fato, devidamente comprovado» (AMS 50.400-SP, DJ 2 12-66, p. 4.244). 
Assim como,

«Ao Poder Judiciário não incumbe, em sua função de contrôle sobrepor-se ou antepor-se à Administração e praticar atos que a esta cabe praticar. Pedidos de readaptação devem ser dirigidos originàriamente ao Executivo, e sòmente para corrigir atos dêste é que cabe ao Judiciário intervir» (AP 20.582-GB, DJ 22-4-66, Apenso, p. 75; AMS 51.567 SP, DJ 3-3-67, p. 429).

«A readaptação depende de processo administrativo, para apuração dos requisitos exigidos e de decreto executivo, que lhe serve de arrcmate e marca ' início da percepção das vantagens» (AMS 45.865-SP, DJ 4-4-66, p. 1.084; 47.719-SP, DJ 16-9-66, p. 3.144; 50.267-SP, ibdem, p. 3.146; 50.210-SP, ibdem, p. $3.146 ; 50-82-S P$, ibdem, p. 1.469; 46.314-BA, DJ 22-5-67, p. 1.468$)$.

Por isso mesmo, reconhece o Tribunal Federal de Recursos:

«Aberta ao servidor oportunidade de readaptação, não pode a Administração fraudá-la, mediante dispensa do interessado, mas abrir processc em qile se examine o seu direito» (AMS 26.427GB, DJ 12-6-64, Apenso, p. 508);

«Direito ao respectivo processo. O servidor, que se julga nas cundições legais, tem direito a ver instalado o processo de readaptação de seu interêsse» (AMS 45.866-SP, DJ 18-4-66, p. 1.214);

«O servidor que requer a sua readaptação tem direito a que se forme o processo correspondente e o mesmo tenha andamento» (AMS 38.624, DJ 6-10-64, p. 3.600).

Assim, «deve o funcionário aguardar que a administração examine e julgue a sua readaptação, desde que não confirmada desídia ou omissão da autoridade na apreciação de pedido» (AMS 51.497-SP, DJ 31 10-66, p. 3.789).

E. a posteriori, a via ordinária, hoje pràticamente exeqüível com mais rapidez, em virtude das restrições impostas ao mandado de segurança pela Lei 4.348-64 (art. $5^{\circ}$ parágrafo único).

"Ato que reclassifica, reenquadra ou readapta servidor ou funcionário não se impugna em processo de mandado de segurança, pois sua apreciação envolve numerosos elementos de fato. e confronto de situações, o que só se conjuga com processo administrativo individual e, a posteriori, vias ordinárias» (AMS 43.723, DJ 2-9-66, p. 2.965; 43.976-GB, DJ 6-5-66 p. 1.473; 45.641-SP, ibdem, p. 1.474; 43.600-SP, DJ 30-9-66, p. 3.340; 51.425-SP, DJ 25-11-66, p. 4.146).

Conceitua o Egrégio Tribunal Federal de Recursos a readaptação,

«o exercício de fato de cargo diverso daquele em que o servidor é provido, pode gerar direito à readaptação de que 
trata o art. 43 da Lei $n^{9} 3.780-60$ e não à percepção dos vencimentos do cargo exercido» (AMS 44.315-GB, DJ 2-9-66, p. 2.966; 51.536-SP, DJ $12-5-67$, p. 1.363);

porque

"A simples expectativa da readaptação não gera nenhum direito» (AMS 50.452-SP, DJ 25-4 67, p. 1.106; 50.419-SP, ibdem, p. 1.106; 45.520-SP, DJ 14-4 67, p. 983; 50.312-SP, ibdem, p. 985; 50.374-SP, ibdem, p. 985; Embargos Ap .... 19.649-GB, DJ 11-4-67, p. 902; AMS 45.076-SP, DJ 24-2-67, p. 336; 50.165-SP, DJ 25 11-66, p. 4.244; 50.402-SP, 48.916-SP, 49.608-SP, 45.856-SP; 51.778-SP, todos DJ 2-12-66, p. 4.244; $4.243 ; 4.243 ; 4.241$ e 4.241);

também,

«Readaptação ainda em processamento não confere a funcionário direito aos vencimentos do cargo pretendido» (AMS 43.704-SP, DJ 17-2 67, p. 214; 47.310-SP, DJ $17-2-67$, p. 217; 44.657-GB, ibdem, p. 215; 50.313-SP, DJ 3-3-67, p. 428);

assim como,

«A readaptação de que trata o art. 43 da Lei $n^{\circ} \quad 3.780-60$. Direito que assiste ao funcionário, além do assegurado pelo art. 16 do Decreto $n^{\circ} 49.370$, é o de ser mantido nas fúnções que vem exercendo sen fazer jus, entretanto, às vantagens patrimoniais respectivas» (AMS 44.192-SP, DJ 12-10-65, p. 2.747; 43.231 SP, DJ 4-7 66, p. 2.349; 45.559-SP, ibdem, p. 2.352; 47.328-SP, ibdem 2.356; 47.499-SP, ibdem, p. 2.356; 46.070SP, DJ 8-8-66, p. 2.613; 43.302-SP, DJ 22-8-66, p. 2.768 , e outros).

Em julgados isolados, no entanto, reconhece-se:

«Havendo, porém, exercício de fato, devidamente comprovado, o servidor deve perceber os vencimentos do cargo em quc já se encontra em exercício» (AMS 50.400-SP, DJ 2-12-66, p. 4.244);

e

«Não obstante o processo de readaptação, o servidor pode perceber, desde logo, as vantagens do cargo, se ocorre exercício de fato comprovado» (AMS 48.911-SP, DJ 30-9-66, p. 3.355).

Mas prevalece, pelo número de julgados, que:

"O instituto da readaptação, investindo o servidor no "nôvo cargo, por efeito de transformação, sòmente produz efeitos ex nunc, não só porque a sua eficácia jurídica tem início a contar da data da publicação do decreto no órgão oficial, como também porque a investidura no cargo é que tem capacidade para fazer 
com que, de então em diante, o funcionário readaptado adquira uma nova situação jurídica de ordem funcional e patrimonial» (AMS 36.699-SP, DJ 29-9-66, p. 2.594; 43.671-SP, ibdem, p. $2.598 ; 45.885-S P$, DJ $5-10-65$, p. $2.663 ; 30.835-S P$, DJ 26-11-65, Apenso, p. 564; 45.606-SP, DJ 19-8-66, Apenso, p. 162; 38.884-SP, DJ 5-11-65, Apenso, p. 543; 44.850-AM, DJ 26 de outubro de 1965 , p. 2.945; 44.275-SP, DJ 20-11-65, p. 2.875).

Com relação à aplicação da readaptação ao funcionário aposentado, ainda divergem os julgados, entendendo o Supremo Tribunal Federal que caberia a aplicação do instituto (Agravo 39.317-GB, DJ 15-6-67, p. 1.831), enquanto que, no Tribunal Federal de Recursos, há uma decisão aceitando a aplicação (Apelação Civel 18.776, DJ 7-7-64, p. 2.211), e uma, mais recente, negando, sob a invocação de que:

«com a aposentadoria, o servidor deixa o cargo público e passa à condição de pensionista do Estado, pelo que incompativel com essa situação é sua readaptação funcional» (AMS 51.453-BA, DJ 21-12-66, p. 4.477).

Outros princípios estabelecidos pelo Judiciário (TFR) merecem indicação, como seja:

«Constitui condição para efetivação da readaptação a aprovação do enquadramento defintivo» (AMS 31.537, DJ 12-8-64, p. 2.819);

«Não há como readaptar funcionário em cargo inexistente no órgão a que pertence» (Ap 22.763-GB, DJ 21-3-67, p. 668; Ap. 21.820-GB, DJ 8-5-67, p. 1.286). 